\title{
A Histologic and Histomorphometric Analysis of Bone Tissue Regeneration with Perforated Bone Allograft in Rabbit Femur Defect
}

\author{
B. E. Tuleubaev ${ }^{1}$, E. K. Kamyshansky ${ }^{2}$, Saginova Dina Azimovna ${ }^{1 *}$, E. R. Tashmetov ${ }^{1}$, A. A. Koshanova ${ }^{1}$ \\ ${ }^{1}$ Department of Surgical Diseases, Karaganda Medical University, Karaganda, Kazakhstan; ${ }^{2}$ Laboratory and Pathological Unit, \\ Clinic of Karaganda Medical University, Karaganda, Kazakhstan
}

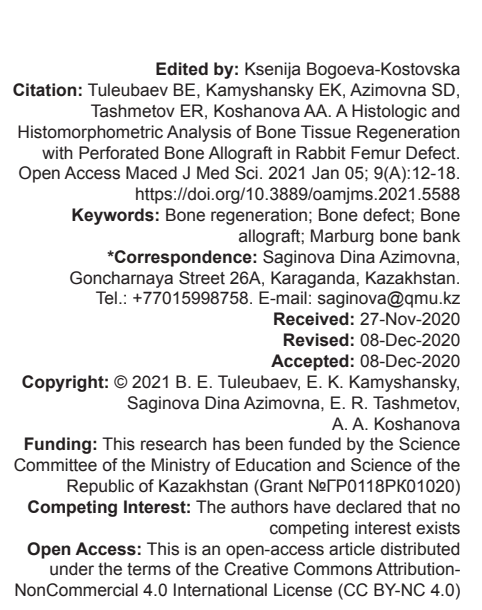

Abstract

AIM: The aim of this study is to provide a comparative histopathological evaluation of the regeneration of bone defect filling with perforated antibiotic-impregnated bone allograft.

MATERIALS AND METHODS: Seventy-two healthy rabbits (24 rabbits in each group) were used for this study Bone defects (3-mm diameter, 10-mm depth) were created in the femur. Human femoral head prepared according to the Marburg bone bank system was used as a bone allograft. The control group did not receive any filling. The experimental groups were as follows: Group 1 - the defects were filled with bone allografts and Group 2 - Perforated gentamycin-impregnated bone allografts. The animals were euthanized after 14, 30, and 60 days. Evaluations consisted of histology at 14-, 30-, and 60-days post-surgery.

RESULTS: A mature bone formation in the group without a bone allograft occurred after 30 days and the group with an allograft after 14 days. In the groups with an allograft, a bone marrow defect was noted as complete closure afte 30 days. Histomorphometric analysis showed that in the group with an antibiotic-impregnated bone, allograft leads to increased resorption of the allograft in the intramedullary space compared to group without antibiotic.

CONCLUSION: We believe that a perforated allograft as a result of clinical trials may be obvious and economically affordable in the treatment of bone defects. The use of gentamycin-impregnated bone allografts may be of value in the prevention and treatment of bone infections.

\section{Introduction}

The recovery of bone defects caused by various causes such as tumors, infections, and trauma is a complicated area of orthopedics medicine [1], [2]. At present, various methods are being used for reconstruction and repair of lost bone tissues [2], [3]. One of these methods is the use of autogenous or allogeneic bone grafts. Every year, more than two million bone transplantation procedures are performed worldwide, which is the second most common tissue transplant after blood transfusion [2], [4], [5]. Transplants perform the functions of mechanical support and osteoregeneration, including osteoconduction, osteoinduction, and osteogenesis [6]. The clinical choice of biomaterials depends on many factors, including etiopathogenetic aspects, the severity of the damage, financial and economic costs, and many other factors [1], [7]. The study of the biological properties of various materials is used for bone grafting and the search for new materials is an urgent problem [2], [4].
Combination of an allograft with an antibiotic is also often used to treat or prevent bone infection [8], [9]. There is some research on the effect of antibiotics on bone regeneration. The usefulness of antibiotics in osseous grafts has been controversial [10], [11]. Fassbender et al. reported that using freeze-dried bone allografts in combination with local gentamicin does not interfere osseous regeneration [12]. This agrees with an earlier report that indicated uniformly successful treatment of defects using the same treatment regimen [13], [14]. Durmuşlar et al. also reported better results by combining antibiotics with bone grafts than with the use of graft alone [15]. On the contrary, several other studies have shown that the integration of antibiotics in graft material had a depressive effect on bone formation [16], [17], [18]. However, in all these studies, lyophilized bone autografts or freeze-dried ones were used, there are no data in the available literature on antibiotic impregnation of heat-treated bone grafts. In this study, bone regeneration was assessed using bone allograft prepared by Marburg system with and without antibiotic impregnation. 


\section{Materials and Methods}

\section{Preparation of bone allografts}

For this study, the femoral heads were used, which were obtained from a living donor (in patients after arthroplasty surgery on the hip joint) according to the national low. The experiment included heads of the femur with a diameter of $50-55 \mathrm{~mm}$, without sclerosis and damage. Bone allografts were perforated according to the developed technique [19]. In brief, perforations were made in the head of the femur using a special device at an equal distance. Next, heat treatment was carried out according to the Marburg Bone Bank System in Lobator sd-2 sterilizer (Telos Company, Germany) [20].

\section{Animals and surgical procedures}

In this study, 72 outbred rabbits were enrolled, all adult animals (under 5 months of age) with a weigh $2225 \pm 63 \mathrm{~g}$. The European Convention for the protection of vertebrate animals used for experimental and other scientific purposes (2010) was followed during all stages of research. All procedures were approved by the Ethics Committee of Karaganda Medical University (№13 25.09.2017). The rabbits were placed in special cages. Throughout the study, the rabbits were kept at room temperature $\left(22 \pm 2^{\circ} \mathrm{C}\right)$ at $40-50 \%$ humidity and under a 12 -h light-dark cycle. The rabbits were fed standard rabbit pellets and tap water.

The rabbits were randomly divided into three experimental groups ( $n=24$ in each group). All rabbits received the same surgical procedure. General anesthesia was induced a mixture of ketamine $35 \mathrm{mg} / \mathrm{kg}$ and xylazine $5 \mathrm{mg} / \mathrm{kg}$, which was administered intramuscularly. Each rabbit was stabilized on the operating table. After cutaneous incision, bone defects were formed in the metaphysis of the femur using a drill with a diameter of $3 \mathrm{~mm}$ and a depth of $10 \mathrm{~mm}$. In the first, experimental group, the bone defects were filled with a perforated bone allograft. In the second, experimental group, the defects were filled with a perforated antibiotic-impregnated bone allograft. Before the operation, the bone allografts were soaked in a $40 \mathrm{mg} / \mathrm{ml}$ gentamicin solution at room temperature for $1 \mathrm{~h}$. In the third, control group, the bone defects were left empty and allowed to heal spontaneously. The wounds were closed with absorbable sutures (№04) and disinfected. The post-operative observation was performed daily to check the progress of healing according to a pre-planned schedule during consecutive days. There were no complications or deaths in the post-operative period.

Animals were sacrificed in groups of 8 animals on the $14^{\text {th }}, 30^{\text {th }}$, and $60^{\text {th }}$ days after surgery.

\section{Histological examination}

Animals were euthanized with an overdose of intravenous anesthesia. Bone samples were taken on days 14,30 , and 60 after the surgery and processed for histological analysis.

The femur was resected in the area of surgical intervention with adjacent soft tissues. Tissues were fixed for at least $18 \mathrm{~h}$ in a $10 \%$ formalin solution and then decalcified with $10 \%$ formic acid. After macroscopic evaluation, bone fragments were placed in paraffin. After this, the samples were longitudinally sectioned in $5 \mu \mathrm{m}$ slices from different parts of areas. The sections were stained with hematoxylin and eosin for light microscopic observation. Microscopic examinations were done in an optic microscope at 100x. Furthermore, to evaluate bone mineralization, growth, and maturation, additional sections of bone tissue were stained using Masson's Trichrome.

The morphometric evaluation was carried out on an area of $1 \mathrm{~cm}^{2}$ in the place where the surgery was performed (defect formed). Histological evaluation criteria are presented in Table 1.

Table 1: Histological criteria for morphometric assessment

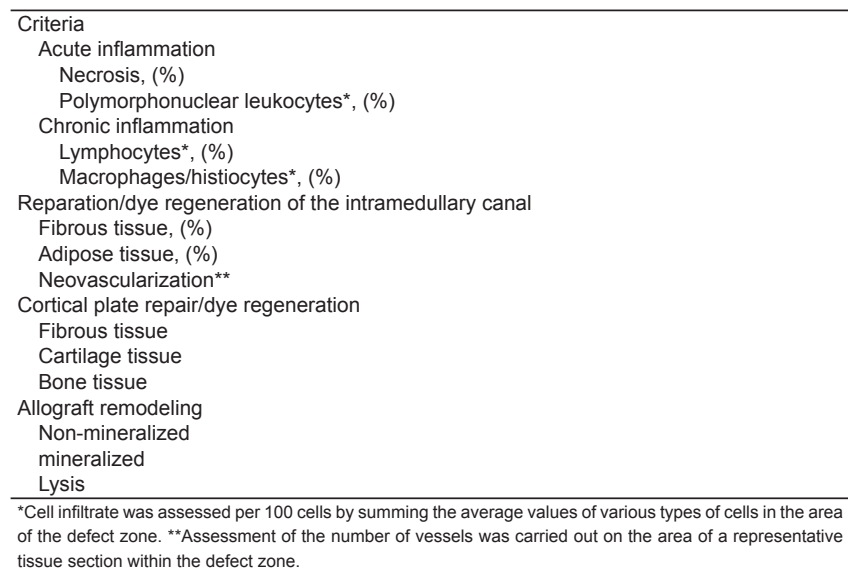

\section{Statistical analysis}

Statistical processing of research results was analyzed using IBM SPSS Statistics 20.0. Values are presented as mean and standard deviations. Comparisons between groups were performed with the Chi-square test. A $p<0.05$ was considered as statistically significant.

\section{Results}

Tables 2-4 and Figure 1 present the results of a comparative histomorphometric analysis of the reparative regeneration of bone tissue using a perforated bone allograft in an animal experiment. 
Table 2: Comparative histological analysis of the reparative process in the zone of the defect on the $14^{\text {th }}$ day of the experiment

\begin{tabular}{|c|c|c|c|c|c|c|c|c|}
\hline \multirow[t]{2}{*}{ Histological characteristic } & \multicolumn{5}{|l|}{ Groups (n) } & \multicolumn{3}{|l|}{$\mathrm{p}$-value } \\
\hline & group $(n=8)$ Mean \pm SD & II group $(\mathrm{n}=8)$ & Mean \pm SD & III group $(n=8)$ & Mean \pm SD & $\mathrm{a}$ & $\mathrm{b}$ & c \\
\hline \multicolumn{9}{|l|}{ Inflammation } \\
\hline \multicolumn{9}{|l|}{ Acute (\%) } \\
\hline Necrosis & $1.38 \pm 0.92$ & 0 & & 0 & & $0.002^{*}$ & $0.002^{*}$ & - \\
\hline Granulocytes & $1.38 \pm 1.51$ & $12.5 \pm 1.93$ & & $1.63 \pm 1.41$ & & $0,001^{*}$ & 0.574 & $0.001^{*}$ \\
\hline \multicolumn{9}{|l|}{ Chronic (\%) } \\
\hline Lymphocytes & $15.7 \pm 3.93$ & $31.3 \pm 6.37$ & & $36.3 \pm 5.70$ & & $0.000^{*}$ & $0.000^{*}$ & 0.130 \\
\hline Macrophages & $18.4 \pm 4.5$ & $20.3 \pm 2.31$ & & $19.25 \pm 4.62$ & & 0.505 & 0.442 & 0.798 \\
\hline \multicolumn{9}{|c|}{ Reparative/Disregenerative pattern in the intramedullary canal fibrous tissue } \\
\hline Fibrous tissue & $41.8 \pm 4.2$ & $6.9 \pm 1.33$ & & $7.1 \pm 1.46$ & & $0.000^{*}$ & $0.000^{*}$ & 0.798 \\
\hline Adipose tissue & $55.8 \pm 4.86$ & $17.4 \pm 4.03$ & & $19.5 \pm 2.83$ & & $0.000^{*}$ & $0.000^{*}$ & 0.234 \\
\hline Neovascularization & $11.6 \pm 3.78$ & $10.0 \pm 3.85$ & & $13.9 \pm 3.76$ & & 0.328 & 0.130 & 0.083 \\
\hline \multicolumn{9}{|c|}{ Reparative/Disregenerative pattern cortical plate (\%) } \\
\hline Fibrous tissue & $76.1 \pm 3.55$ & $22.6 \pm 4.36$ & & $20.3 \pm 2.29$ & & $0.000^{*}$ & $0.000^{*}$ & 0.328 \\
\hline Cartilage tissue & $11.2 \pm 2.17$ & $3.00 \pm 1.73$ & & $1.63 \pm 0.99$ & & $0.000^{*}$ & $0.000^{*}$ & 0.105 \\
\hline Bone tissue & $12.6 \pm 5.52$ & $74.4 \pm 4.53$ & & $78.0 \pm 2.29$ & & $0.000^{\star}$ & $0.000^{*}$ & 0.130 \\
\hline \multicolumn{9}{|l|}{ Allograft remodeling } \\
\hline Non-mineralized & - & $53.0 \pm 6.20$ & & $50.4 \pm 4.64$ & & - & - & 0.645 \\
\hline Mineralized & - & $27.9 \pm 7.56$ & & $22.3 \pm 2.44$ & & - & - & 0.195 \\
\hline Lysis & - & $19.1 \pm 8.9$ & & $27.4 \pm 5.19$ & & - & - & 0.065 \\
\hline
\end{tabular}

Table 3: Comparative histological analysis of the reparative process in the zone of the defect on the $30^{\text {th }}$ day of the experiment

\begin{tabular}{|c|c|c|c|c|c|c|}
\hline \multirow[t]{2}{*}{ Histological characteristic } & \multicolumn{3}{|l|}{ Groups (n) } & \multicolumn{3}{|l|}{$\mathrm{p}$-value } \\
\hline & Igroup $(n=8)$ Mean \pm SD & II group $(n=8)$ Mean \pm SD & III group $(n=8)$ Mean $\pm S D$ & $a$ & $\mathrm{~b}$ & $\mathrm{c}$ \\
\hline \multicolumn{7}{|l|}{ Inflammation } \\
\hline \multicolumn{7}{|l|}{ Acute (\%) } \\
\hline Necrosis & 0 & 0 & 0 & - & - & - \\
\hline Granulocytes & 0 & 0 & 0 & - & - & - \\
\hline \multicolumn{7}{|l|}{ Chronic (\%) } \\
\hline Lymphocytes & $11.3 \pm 2.63$ & $27.1 \pm 4.01$ & $11.6 \pm 2.12$ & $0.000^{*}$ & 0.564 & $0.000^{*}$ \\
\hline Macrophages & $7.3 \pm 1.3$ & $33.8 \pm 4.58$ & $16.5 \pm 4.18$ & $0.000^{*}$ & $0.000^{*}$ & $0.000^{*}$ \\
\hline \multicolumn{7}{|c|}{ Reparative/Disregenerative pattern in the intramedullary canal fibrous tissue (\%) } \\
\hline Fibrous tissue & $10.4 \pm 1.32$ & $7.3 \pm 1.30$ & $6.4 \pm 1.32$ & $0.001^{*}$ & $0.000^{*}$ & $0.000^{*}$ \\
\hline Adipose tissue & $83.0 \pm 2.24$ & $39.3 \pm 3.96$ & $44.6 \pm 8.48$ & $0.000^{*}$ & $0.000^{*}$ & 0.161 \\
\hline Neovascularization & $11.3 \pm 3.38$ & $17.1 \pm 2.32$ & $16.3 \pm 2.11$ & $0.002^{*}$ & $0.003^{*}$ & 0.505 \\
\hline \multicolumn{7}{|c|}{ Reparative/Disregenerative pattern cortical plate (\%) } \\
\hline Fibrous tissue & $14.8 \pm 3.56$ & $1.75 \pm 1.09$ & $1.38 \pm 0.70$ & $0.000^{*}$ & 0.442 & 0.645 \\
\hline Cartilage tissue & $9.0 \pm 4.92$ & $7.63 \pm 5.72$ & $7.13 \pm 7.10$ & 0.721 & 0.442 & 0.798 \\
\hline Bone tissue & $76.9 \pm 3.99$ & $90.6 \pm 6.50$ & $91.5 \pm 6.95$ & $0.000^{*}$ & $0.000^{*}$ & 0.878 \\
\hline \multicolumn{7}{|l|}{ Allograft remodeling } \\
\hline Non-mineralized & - & $43.3 \pm 12.41$ & $45.8 \pm 15.23$ & - & - & 0.654 \\
\hline Mineralized & - & $29.1 \pm 7.30$ & $21.1 \pm 6.31$ & - & - & 0.050 \\
\hline Lysis & - & $27.6 \pm 17.8$ & $33.1 \pm 17.74$ & - & - & 0.442 \\
\hline
\end{tabular}

Table 4: Comparative histological analysis of the reparative process in the zone of the defect on the $60^{\text {th }}$ day of the experiment

\begin{tabular}{|c|c|c|c|c|c|c|}
\hline \multirow[t]{2}{*}{ Histological characteristic } & \multicolumn{3}{|l|}{ Groups (n) } & \multicolumn{3}{|l|}{$\mathrm{p}$-value } \\
\hline & I group $(n=8)$ Mean \pm SD & II group $(n=8)$ Mean \pm SD & III group $(n=8)$ Mean $\pm S D$ & $\mathrm{a}$ & $\mathrm{b}$ & C \\
\hline \multicolumn{7}{|l|}{ Inflammation } \\
\hline \multicolumn{7}{|l|}{ Acute (\%) } \\
\hline Necrosis & 0 & 0 & 0 & - & - & - \\
\hline Granulocytes & 0 & 0 & 0 & - & - & - \\
\hline \multicolumn{7}{|l|}{ Chronic (\%) } \\
\hline Lymphocytes & $9.7 \pm 2.49$ & $22.6 \pm 2.60$ & $11.0 \pm 1.32$ & $0.000^{*}$ & 0.195 & $0.000^{*}$ \\
\hline Macrophages & $8.63 \pm 1.22$ & $9.75 \pm 1.71$ & $8.75 \pm 1.85$ & 0.234 & 0.878 & 0.234 \\
\hline \multicolumn{7}{|c|}{ Reparative/Disregenerative pattern in the intramedullary canal fibrous tissue (\%) } \\
\hline Fibrous tissue & $8.6 \pm 1.5$ & $3.2 \pm 1.7$ & $2.6 \pm 0.9$ & $0.000^{*}$ & $0.000^{*}$ & 0.326 \\
\hline Adipose tissue & $89.4 \pm 7.16$ & $64.9 \pm 4.11$ & $67.8 \pm 6.35$ & $0.000^{*}$ & $0.001^{*}$ & 0.574 \\
\hline Neovascularization & $10.0 \pm 1.87$ & $20.1 \pm 3.41$ & $20.6 \pm 2.60$ & $0.000^{*}$ & $0.000^{*}$ & 0.721 \\
\hline \multicolumn{7}{|c|}{ Reparative/disregenerative pattern cortical plate (\%) } \\
\hline Fibrous tissue & $8.75 \pm 4.05$ & $0.75 \pm 1.09$ & $0.88 \pm 1.05$ & $0.000^{*}$ & $0.000^{*}$ & 0.798 \\
\hline Cartilage tissue & $8.5 \pm 2.7$ & $6.5 \pm 4.77$ & $8.3 \pm 7.28$ & 0.798 & 1.000 & 0.878 \\
\hline Bone tissue & $85.0 \pm 7.35$ & $91.3 \pm 7.36$ & $94.0 \pm 2.55$ & 0.161 & 0.083 & 0.959 \\
\hline \multicolumn{7}{|l|}{ Allograft remodeling (\%) } \\
\hline Non-mineralized & - & $32.6 \pm 4.5$ & $25.1 \pm 9.32$ & - & - & 0.161 \\
\hline Mineralized & - & $27.9 \pm 7.56$ & $17.6 \pm 6.06$ & - & - & $0.028^{*}$ \\
\hline Lysis & - & $39.5 \pm 10.5$ & $57.3 \pm 14.57$ & - & - & $0.050^{*}$ \\
\hline
\end{tabular}

\section{Group 1}

The morphological pattern of the reparative process in the cortical bone was characterized by a progressive increase in mature bone tissue with minimal fibrosis. At 14 days, the defect zone is predominantly represented by bone tissue $(74.4 \%)$ with active longitudinal and transverse growth of bone beams located between the edge of the bone plate and allograft fragments. The closure of the defect occurs mainly due to the growth from the edge of the cortical bone. At 30 and 60 days, there is a total closure of the bone plate in the defect area with the predominance of mature bone tissue with a high degree of mineralization.

The reparative/disreparative pattern of the intramedullary zone of a bone defect was characterized by a gradual dynamic increase in the relative amount of mature adipose tissue of the bone marrow due to allograft resorption by 30 and 60 days.

Histological signs of acute inflammation at all times $(14,30$, and 60 days) were not detected. 


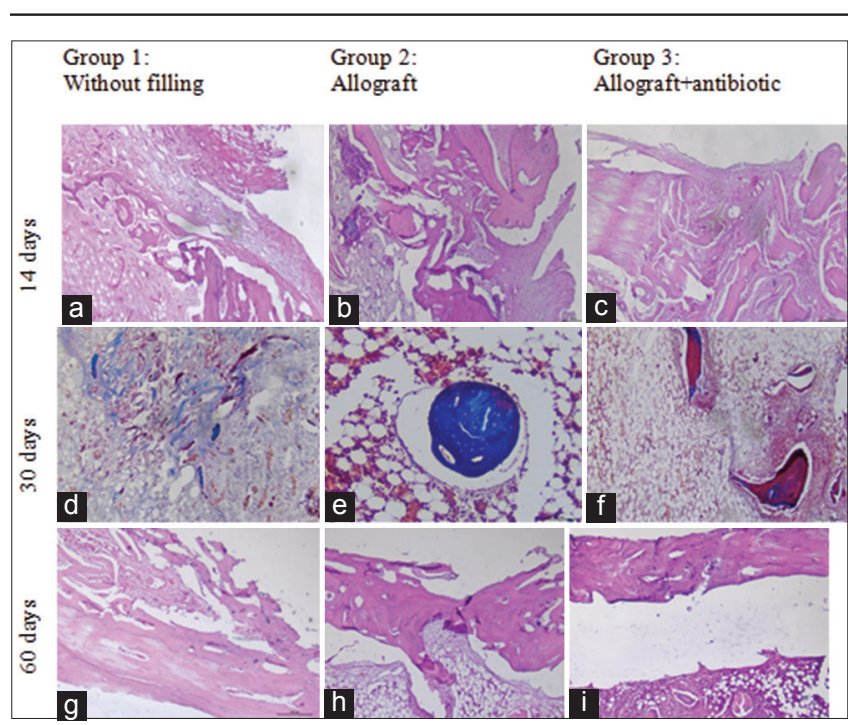

Figure 1: (a-c) G-I - bone plate in the area of the defect. Hematoxylin and eosin stain. 100×. (d-f) intramedullary space. Masson's Trichrome stain. 100x. (a) Partial (up to 20\%) closure of the defect area with coarse fibrous connective tissue; transverse growth of bone beams is noted from the edge of the bone plate. ( $b$ and $c$ ) Closure of a bone defect with fibrocartilaginous callus without active signs of an inflammatory process with reactive lymphohistiocytic infiltration. (g-i) Complete restoration of the bone plate with complete longitudinal growth without an active inflammatory process. (d) The growth of coarse fibrous connective tissue with reactive angiosis and perifocal lymphohistiocytic infiltration. (e) Fragment of a mineralized allograft without perifocal reactive inflammation. (f) Active remodeling of the intramedullary space: The immune environment in peri allograft zones, continued lysis, and resorption of a non-mineralized bone allograft

In all periods, limited intramedullary lymphomacrophagic infiltration was observed in the perifocal zones of the allograft without signs of fibrosis.

\section{Group 2}

The bone tissue in the defect zone was characterized by reparative processes with an increase in the relative amount of mature bone tissue at 14,30 , and 60 days. On day 14, bone tissue prevailed in the area of the bone plate.

The reparative/disreparative pattern of the intramedullary zone of a bone defect was characterized by increased lysis and resorption of the allograft with a dynamic, progressive decrease in the content of the allograft in the intramedullary space.

Histological signs of acute inflammation at all times $(14,30$, and 60 days) were not detected.

\section{Group 3}

The morphological pattern of the reparative process in the cortical plate was characterized by a prolonged persistence of fibrous tissue. At 14 days, the defect zone is represented mainly by coarse fibrous connective tissue $(76.1 \%)$ with reactive angiosis and perifocal lymphohistiocytic infiltration. The closure of the defect occurs mainly due to the growth from the edge of the cortical bone. At 30 and 60 days, the defect zone is mainly represented by bone tissue with a high degree of mineralization and active longitudinal growth.

The reparative/disreparative pattern of the intramedullary zone of a bone defect was characterized by focal persistence of the coarse fibrous connective tissue at 14 days with subtotal reconstruction and remodeling of the bone marrow canal with a dynamic increase in the relative amount of mature adipose tissue of the bone marrow by 30 and 60 days.

The acute inflammatory pattern was determined on the $14^{\text {th }}$ day of the experiment and was focal in nature: Single polymorphonuclear leukocytes are located mainly on the border of the coarse fibrous connective tissue with reactive angiosis. At 30 and 60 days of active acute inflammation were not detected.

A chronic inflammatory pattern was observed in all experimental periods and was characterized by a mild degree of 14 and 30 days with a tendency to a decrease in the relative amount by 60 days.

\section{Discussion}

In this experimental animal study, a comparative histomorphometric analysis of the pattern of reparative regeneration of bone tissue was carried out with a comparative assessment of the biocompatibility and osteoconductive properties of a bone allograft prepared according to the Marburg Bone Bank System.

An important result of the study is that a perforated allograft showed high biocompatibility. At all stages of the reparative process - in both experimental groups, there were no morphological signs of an active acute inflammatory pattern and a severe chronic inflammatory process. By 30 days in all groups with an allograft, the number of polymorphonuclear leukocytes did not statistically significantly different from the comparison group without filling in a bone defect $(p=0.000)$.

In previously published works, it was shown that the biocompatibility reaction is a dynamic process superimposed on the peculiarities of the reparativeregenerative process, and the type and population of cells at the contact site gradually change during healing [21]. The sequence of local events is usually regarded as a continuum of tissue response, in which each individual event leads to the following: in some cases, trauma passes into acute inflammation, which can turn into chronic inflammation with subsequent formation of granulation tissue [22], [23]. The presence of eosinophils and polymorphonuclear cells is typical for acute inflammatory reactions, and macrophages and fibroblasts - for a chronic form [24]. As a rule, in 
acute inflammation at the site of traumatic injury, the peak of neutrophils occurs 1-2 days after the injury and gradually disappears after 7-10 days, followed by the migration of macrophages 1-2 days after the injury [25]. Fibroblasts and macrophages quantitatively increase one to 2 weeks after surgery and decrease after 6 weeks [23], [24]. One of the informative criteria for biocompatibility disturbance is increased amounts and prolonged persistence of macrophages at the interface with tissue [26], [27], [28], [29].

In this study, a small number of macrophages were found which were not statistically significantly different from each other ( 2 and 3 groups) on 60 days after surgery $(p=0.000)$. This data indicate a high level of biocompatibility.

Further, we found that in the group with an allograft without antibiotic, along (at 30 and 60 days) locoregional persistence of lymphocytic infiltrate (Score 1 and Score 2) was observed at the border of the allograft with remodeled bone tissue with an increase in the number of lymphocytes, which was statistically significantly different from the group with perforated allograft with an antibiotic $(p=0.000)$. It was previously shown that the biocompatibility of materials depends on biological events occurring at the interface between the biomaterial and the surrounding tissue [29]. We believe that the persistence of mild immune cells (Score 1) in the group with a perforated allograft in comparison with an allograft soaked in antibiotic does not reflect the true chronic inflammatory process but is a reactive immunological reaction associated with bone marrow canal remodeling and allograft lysis since in sections of histological sections with a completely remodeled allograft, there is no immune environment at the interface between the allograft and body tissues (Figure 1e).

Histomorphometric analysis showed that the use of a perforated antibiotic-impregnated bone allograft leads to increased lysis and resorption of the allograft in the intramedullary space. In 2 groups, the average amount of resorbed allograft in the intramedullary space at day 60 of the experiment was statistically significantly less than in the 3 groups ( $p=0.05$ ). This difference may be due to the fact that treatment of the allograft with an antibiotic helps to eliminate and level additional stress-induced factors during the repair process that affect the staging of the regeneration process, but this assumption requires further study.

It was further established that a perforated bone allograft has good osteoconductive and osteoinductive properties. In groups using an allograft for 30 days, more than $50 \%$ of the bone plate area is represented by newly formed mature bone tissue, in contrast to the control group. The results obtained are consistent with the data of other researchers [30], [31], [32]. The reason for the improved osteoconductive and osteoinductive properties of a perforated allograft may be an increase in the reference surface area, as well as the possibility of using a mechanical framework for the ingrowth of cellular and vascular components with the formation of a new bone.

There were no differences in the volume of newly formed bone tissue in the area of the formed defect between the two experimental groups using an allograft at 30 and 60 days ( $p=0.878$ and $p=0.959$, respectively). We did not identify any statistical differences $(p=0.161$ and $p=0.083$ ) with respect to restoration of the bone plate with mature bone tissue between groups with allograft, both with and without antibiotics.

On the basis of a dynamically positive reparative process, the absence of signs of an allergic reaction, the spread of tissue necrosis in groups with allograft, no negative toxic effect of the antibiotic on the repair process, and surrounding bone tissue and bone marrow tissue were revealed. However, this assumption is speculative in nature and requires additional research in the future.

Thus, we showed that both biomaterials used in this study as grafts for filling of bone defect formed have good biocompatibility and osteoconductive properties without an osteotoxic effect with or without an antibiotic. At the same time, it was established that a bone allograft not impregnated with an antibiotic is less actively absorbed, but the severity of mineralization did not depend on the use of the antibiotic. It was revealed that when using an allograft, a locoregional light prolonged reactive persistence of immune cells of a chronic inflammatory pattern is observed. This chronic pattern is not a criterion of inflammation but reflects the "immune environment" of peri allograft zones and is associated with the normal process of intramedullary remodeling and recovery. This immune environment can mimic the histological sign of chronic active inflammation, which can lead to misinterpretation of the stage-specific repair process. Both biomaterials with and without antibiotics did not affect the normal processes of bone repair and the formation of mature bone tissue at the site of the defect formed in the long term.

\section{Conclusion}

We believe that a perforated allograft from the perspective of clinical trials may be a worthy and affordable biological material in the bone defects plastic.

\section{References}

1. Nauth A, Schemitsch E, Norris B, Nollin Z, Watson JT. Criticalsize bone defects: Is there a consensus for diagnosis and treatment? J Orthop Trauma 2018;32(1):S7-11. https://doi. org/10.1097/bot.0000000000001115 
PMid:29461395

2. Wang W, Yeung KW. Bone grafts and biomaterials substitutes for bone defect repair: A review. Bioact Mater. 2017;2(4):224-47. https://doi.org/10.1016/j.bioactmat.2017.05.007 PMid:29744432

3. Jörg AA, Brigitte VR, Marc B, Margarethe HA. Bone grafts and bone replacements. In: Musculoskeletal System. Amsterdam, Netherlands: Elsevier; 2014. p. 1081-95.

4. Fesseha H, Fesseha Y. Bone grafting, its principle and application: A review. Osteol Rheumatol Open J. 2020;1(1):43-50.

5. Campana V, Milano G, Pagano E, Barba M, Cicione C, Salonna $G$, et al. Bone substitutes in orthopaedic surgery: From basic science to clinical practice. J Mater Sci Mater Med. 2014;25(10):2445-61. https://doi.org/10.1007/ s10856-014-5240-2

PMid:24865980

6. Albrektsson T, Johansson C. Osteoinduction, osteoconduction and osseointegration. Eur Spine J. 2001;10(2):96-101.

PMid:11716023

7. Reichert JC, Saifzadeh S, Wullschleger ME, Epari DR, Schütz MA, Duda GN, et al. The challenge of establishing preclinical models for segmental bone defect research. Biomaterials. 2009;30(12):2149-63. https://doi.org/10.1016/j. biomaterials.2008.12.050

PMid:19211141

8. Tavridou A, Lalidou F, Kolios G, Tavridou A, Drosos G. Bone grafts as carriers for local antibiotic delivery for the treatment and prevention of bone infections. Surg Technol Int. 2014;25:239-45. PMid:25433347

9. van Vugt TA, Geurts J, Arts JJ. Clinical application of antimicrobial bone graft substitute in osteomyelitis treatment: A systematic review of different bone graft substitutes available in clinical treatment of osteomyelitis. Biomed Res Int. 2016;2016:6984656. https://doi.org/10.1155/2016/6984656 PMid:26904683

10. Peeters A, Putzeys G, Thorrez L. Current insights in the application of bone grafts for local antibiotic delivery in bone reconstruction surgery. J Bone Jt Infect. 2019;4(5):245-53. https://doi.org/10.7150/jbji.38373

PMid:31700774

11. Metsemakers WJ, Fragomen AT, Moriarty TF, Morgenstern M, Egol KA, Zalavras C, et al, Fracture-related Infection (FRI) Consensus Group. Evidence-based recommendations for local antimicrobial strategies and dead space management in fracture-related infection. J Orthop Trauma. 2020;34(1):18-29. https://doi.org/10.1097/bot.0000000000001615 PMid:31464858

12. Fassbender M, Minkwitz S, Kronbach Z. Local gentamicin application does not interfere with bone healing in a rat model. Bone. 2013;55(2):298-304. https://doi.org/10.1016/j. bone.2013.04.018

PMid:23631877

13. Haleem AA, Rouse MS, Lewallen DG, Hanssen AD, Steckelberg JM, Patel R. Gentamicin and vancomycin do not impair experimental fracture healing. Clin Orthop Relat Res. 2004;427:22-4. https://doi.org/10.1097/01. blo.0000144477.43661.59 PMid: 15552131

14. Lindsey RW, Probe R, Miclau T, Miclau T, Alexander JW. The effects of antibiotic-impregnated autogeneic cancellous bone graft on bone healing. Clin Orthop Relat Res. 1993;291:303-12. https://doi.org/10.1097/00003086-199306000-00035 PMid:8504612

15. Durmuşlar MC, Balli U, Türer A, Önger ME, Çelik HH. Radiological and stereological evaluation of the effect of rifampin on bone healing in critical-size defects. J Craniofac Surg. 2016;27(6):1481-5. https://doi.org/10.1097/ scs. 0000000000002762

\section{PMid:27603686}

16. Rathbone CR, Cross JD, Brown KV, Murray CK, Wenke JC Effect of various concentrations of antibiotics on osteogenic cell viability and activity. J Orthop Res. 2011;29(7):1070-4.

PMid:21567453

17. Tuncay I, Ozbek H, Kosem M, Unal O. A comparison of effects of fluoroquinolones on fracture healing (an experimental study in rats). Ulus Travma Acil Cerrahi Derg. 2005;11(1):17-22. PMid:15688263

18. Perry AC, Prpa B, Rouse MS. Levofloxacin and trovafloxacin inhibition of experimental fracture-healing. Clin Orthop Relat Res. 2003;414:95-100. PMid:12966282

19. Tuleubaev BE, Abiev TM, Saginova DA, Saginov A.M., Koshanova AA,Rudenko AP, et al. A Device for Perforating a Bone Allograft. Patent for Utility Model of the Republic of Kazakhstan № 3980: 2019.

20. Pruss A, Seibold M, Benedix F, Frommelt L, von Garrel T, Gürtler $\mathrm{L}$, et al. Validation of the Marburg bone bank system for thermodisinfection of allogenic femoral head transplants using selected bacteria, fungi, and spores. Biologicals. 2003;31(4):28794. https://doi.org/10.1016/j.biologicals.2003.08.002 PMid:14624799

21. Kvist PH, Iburg T, Bielecki M, Gerstenberg M, Buch-Rasmussen $T$, Hasselager $\mathrm{E}$, et al. Biocompatibility of electrochemical glucose sensors implanted in the subcutis of pigs. Diabetes Technol Ther. 2006;8(4):463-75. https://doi.org/10.1089/dia.2006.8.463 PMid: 16939371

22. Anderson JM, Shive MS. Biodegradation and biocompatibility of PLA and PLGA microspheres. Adv Drug Deliv Rev. 1997;28(1):5-24. https://doi.org/10.1016/ s0169-409x(97)00048-3

PMid: 10837562

23. Anderson JM, Rodriguez A, Chang DT. Foreign body reaction to biomaterials. Semin Immunol. 2008;20(2):86-100. https://doi. org/10.1016/j.smim.2007.11.004

PMid:18162407

24. Rihova B. Immunocompatibility and biocompatibility of cell delivery systems. Adv Drug Deliv Rev. 2000;42(1-2):65-80. https://doi.org/10.1016/s0169-409x(00)00054-5 PMid:10942815

25. Houglum PA. In: Perrin DH, editor. Theraputic Exercise for Musculoskeletal Injuries. United States: Human Kinetics; 2005.

26. Shishatskaya El, Volova TG, Puzyr AP, Mogil'naya OA, Efremov SN, Gitelson II, et al. Tissue morphogenesis under the conditions of implantation of polyhydroxybutyrate, a biodegradable polymer. Dokl Biol Sci. 2001;383:123-6. PMid:12053561

27. Christen T, Nahrendorf M, Wildgruber M, Swirski FK, Aikawa E, Waterman $P$, etal. Molecularimaging of innate immune cell function in transplant rejection. Circulation. 2009;119(14):1925-32. https:// doi.org/10.1161/circulationaha.108.796888 PMid: 19332470

28. Xu L, Bauer J, Siedlecki CA, State TP. Proteins, platelets and blood coagulation at biomaterial interfaces. Colloids Surfaces B Biointerfaces. 2014;124:49-68. https://doi.org/10.1016/j. colsurfb.2014.09.040

PMid:25448722

29. Robbins SL, Kumar V, Cotran R. Pathologic Basis of Disease. $5^{\text {th }}$ ed. Netherlands: Elsevier; 1994. p. 61

30. Lewandrowski KU, Schollmeier G, Ekkemkamp A, Uhthoff HK 
Tomford WW. Incorporation of perforated and demineralized cortical bone allografts. Part I: Radiographic and histologic evaluation. Biomed Mater Eng. 2001;11(3):197-207.

PMid: 11564903

31. Lewandrowski KU, Schollmeier G, Ekkemkamp A, Uhthoff HK, Tomford WW. Improved osteoinduction of cortical bone allografts: A study of the effects of laser perforation and partial demineralization. J Orthop Res. 1997;15(5):748-56. https://doi. org/10.1002/jor.1100150518

PMid:9420606

32. Caballe-Serrano J, Schuldt Filho G, Bosshardt DD, GargalloAlbiol J, Buser D, Gruber R. Conditioned medium from fresh and demineralized bone enhances osteoclastogenesis in murine bone marrow cultures. Clin Oral Implants Res. 2016;27(2):226-32. https://doi.org/10.1111/clr.12573

PMid:25754222 